\title{
Agresión en el pipican. Responsabilidad civil objetiva en la aplicación del art. 1905 CC. Comentario a la Sentencia de la Audiencia Provincial de Barcelona de 23-5-2013 (SAP B $5796 / 2013)^{1}$
}

Dra. Maria Ysàs Solanes ${ }^{2}$

\section{Introducción.-}

La Sentencia a comentar resuelve en trámite de apelación el caso presentado en Primera Instancia por la víctima de un mordisco del perro propiedad de la demandada, codemandada juntamente con la Compañía Aseguradora.

La sentencia de Primera Instancia estima íntegramente la demanda basada en la responsabilidad civil extracontractual prevista en el art. $1905 \mathrm{CC}^{3}$ y en el mismo sentido decide la Sentencia de la Audiencia.

De la lectura de esta segunda sentencia, que es el material del que disponemos, parece deducirse que la agresión del perro de raza husky siberiano tuvo lugar en el interior de un "pipican" ${ }^{4}$ y que la mordedura afectó el rostro de la víctima.

Los hechos tan someramente descritos no permiten enjuiciar la situación, ni justifican los fallos de las Sentencias en ambas instancias. Por ello, partiendo del limitado material que nos proporciona la Sentencia en comento, vamos a intentar analizar varias cuestiones, a los efectos de situarnos correctamente en el caso, dejando aparte lo referente a la cuantificación de la indemnización, así como la responsabilidad de la Aseguradora.

En primer lugar es necesario establecer de la forma más apurada posible, teniendo en cuenta las limitaciones del material del que disponemos, cuáles fueron los hechos y las circunstancias en las que acaecieron.

Una segunda cuestión que se plantea es el establecimiento del nexo causal entre la producción del daño y el resultado, así como las interferencias que pudieran haberse dado, lo que necesariamente desemboca en un tercer punto: la interpretación que se hace del art. 1905 CC, respecto a la responsabilidad objetiva del propietario o poseedor del animal en cuestión.

\footnotetext{
${ }^{1}$ http://www.derechoanimal.info/bbdd/Documentos/1106.pdf

2 Profesora Titular de Derecho Civil. Universidad Autónoma de Barcelona

${ }^{3}$ http://www.derechoanimal.info/bbdd/Documentos/605.doc

${ }^{4}$ Zona exclusiva para perros, generalmente habilitada en núcleos urbanos, y en la que los animales pueden permanecer sueltos, relacionarse con otros, hacer sus necesidades...
} 


\section{Determinación de los hechos. Referencia a la Sentencia penal anterior.-}

Centrándonos en el análisis de los hechos llama la atención que la sentencia comentada haga referencia a un procedimiento penal anterior sobre el mismo caso, y lo utilice para excluir una de las alegaciones de la parte demandada en la que dicha parte explica que, en base a hechos acreditados y no negados "fue la recurrente la que se acercó al animal para abrazarlo porque estaba nervioso, que además lo hizo por detrás y de ahí que el perro le mordiese la cara". De lo anterior, la Audiencia deduce que tal alegación no puede prosperar porque la sentencia penal "no es vinculante" en el presente caso, por dos razones: "En primer lugar porque la misma es absolutoria, y en segundo lugar porque los hechos probados no son los que refiere, sino que el acercamiento al perro en el modo en que se pretende, forma parte de los razonamientos jurídicos, es obiter dicta".

Por supuesto que la sentencia penal no es vinculante, especialmente porque el objeto enjuiciado en el procedimiento penal y el objeto enjuiciado en el procedimiento civil son distintos, pero a los efectos de establecer los hechos, una lectura detenida de lo anterior nos proporciona una aproximación bastante segura del escenario real de los hechos, es decir de las circunstancias en las que se desarrolló la acción.

Respecto al segundo argumento esgrimido por la Sentencia comentada, referido a que los hechos relatados en la Sentencia Penal, no son hechos probados sino que forman parte de los razonamientos jurídicos y son obiter dicta, llama la atención que sean traídos a colación porque hace surgir una duda. Es decir, en el caso de que los hechos descritos en la Sentencia Penal hubieran sido ratio decidendi, se habrían tenido en cuenta en la Sentencia Civil, aunque antes se haya afirmado que la sentencia penal no vincula a la sentencia civil (¿ं?).

Veamos, que la Sentencia penal no vincule la decisión civil no excluye que el Tribunal Civil pueda tener en cuenta circunstancias probadas en la vía penal.

En este caso, tal como comentamos, antes del procedimiento civil en el que nos hallamos, hubo un procedimiento penal, y si el Tribunal Penal en la sentencia penal recogió obiter dicta las circunstancias en las que se produjo la agresión, es que éstas se aceptaron como veraces. Por supuesto que no fueron causa decidendi de la sentencia penal, no podían serlo, porque como ya se ha dicho, el objeto del procedimiento penal no fue el mismo que el objeto del procedimiento civil. En el procedimiento penal el objeto era determinar si los hechos encajaban en el supuesto del art. $631 \mathrm{CP}^{6}$ del siguiente tenor:

1. Los dueños o encargados de la custodia de animales feroces o dañinos que los dejaren sueltos o en condiciones de causar mal serán castigados con la pena de multa de uno a dos meses.

\footnotetext{
${ }_{5}^{5}$ Argumentos expuestos en la parte considerativa de una sentencia que, sin carácter vinculante, corroboran la decisión principal.

${ }^{6}$ http://www.derechoanimal.info/bbdd/Documentos/839.doc
} 
2. Quienes abandonen a un animal doméstico en condiciones en que pueda peligrar su vida o su integridad serán castigados con la pena de multa de quince días a dos meses.

Según la sentencia comentada la vía penal terminó con la absolución de la aquí demandada, de lo que es fácil deducir que el perro en cuestión, así como la conducta de su dueña, no encajaban en los presupuestos legales establecidos en el Código Penal, es decir, ni era un animal feroz o dañino que andaba suelto, ni tampoco era un animal doméstico abandonado. Con la absolución en la vía penal queda abierta la vía civil para solicitar, en su caso, la indemnización de los daños causados mediante el ejercicio de la acción de responsabilidad civil extracontractual de acuerdo con el Código Civil.

En consecuencia, mal puede argumentarse que las afirmaciones sobre la sucesión de los hechos son obiter dicta y por ello inaceptables en el proceso civil, cuando lo único de lo que se trataba era de tener una versión lo más cercana posible a los acontecimientos que rodearon la acción productora del daño. Y lo más llamativo es la utilización hecha por la Audiencia de la Sentencia Penal absolutoria, como justificación para no tener en cuenta las circunstancias que allí aparecieron, porque precisamente la absolución liberaba de responsabilidad penal a la demandada, de forma que se utiliza el resultado absolutorio del procedimiento penal en contra de la persona absuelta. Francamente, la aplicación mecánica de los principios procesales sin tener en cuenta la realidad de los hechos hace recapacitar sobre la conveniencia de repasar de vez en cuando lo que establece el Código Civil sobre la interpretación y la aplicación de la ley, porque no debemos olvidar que la ley procesal está para garantizar la protección de los ciudadanos en el proceso y la correcta aplicación de la ley, también de la ley civil.

\section{Determinación del nexo causal. Argumentación de la Sentencia comentada.-}

Siguiendo con la determinación de las circunstancias que rodearon los hechos, debe incidirse en el lugar en el que se produjeron. La agresión tuvo lugar en un "pipican". Aunque parece que todo el mundo sabe de qué se trata, una aproximación a su concepto es oportuna en este caso. Efectivamente, entre las varias definiciones encontradas en Internet he escogido la que da una Clínica Veterinaria, en el siguiente sentido:

"Un Pipican, sería simplemente una zona habilitada especialmente, amplia y vallada donde el suelo fuera de tierra donde se pudiera soltar a los perros sin problemas de accidentes o de escaparse, para que pudieran hacer sus necesidades, en la que debería existir unas papeleras donde los propietarios/as recogieran las heces con una bolsa y las depositaran en las papeleras que serían recogidas con asiduidad".

Por su parte la Ordenanza sobre la protección, tenencia y venta de animales, Acuerdo Consejo Plenario de 22 de diciembre 2003, del Ayuntamiento de Barcelona ${ }^{7}$, en su Artículo 25, referido a Espacios reservados a los animales de compañía, artículo por cierto citado por la sentencia en comento, pero solamente en su segunda parte, establece que:

${ }^{7}$ http://www.derechoanimal.info/bbdd/Documentos/479.pdf 
"1. El Ayuntamiento determinará para los animales de compañía espacios reservados suficientes para el recreo, la socialización y la realización de sus necesidades fisiológicas en condiciones correctas de higiene. Estos espacios deberán garantizar la seguridad de los animales de compañía y de las personas, así como también evitar la huida o pérdida de los animales de compañía. Las personas poseedoras deberán vigilar a sus animales de compañía y evitar molestias a las personas y a otros animales que compartan ese espacio."

Queda claro que un "pipican" es un espacio reservado a los animales de compañía, claramente determinado en cuanto a su superficie, que sirve para que dichos animales de compañía - para el caso que nos ocupa, perros - puedan hacer sus necesidades fisiológicas en condiciones adecuadas, de manera que puedan mantenerse las condiciones higiénicas idóneas en una comunidad urbana.

La insistencia en la función del "pipican" es necesaria dado que la mayoría de animales inteligentes como los perros saben reconocer los lugares y sus funciones. En el caso del perro agente en este caso, se trataba de un perro supuestamente adulto, no consta que se tratara de un cachorro, y no es aventurado pensar que sabía lo que se esperaba de él en el lugar donde se hallaba.

Lo que no queda explicado por los hechos es qué hacía la persona agredida en el "pipican", ya que meterse en un "pipican" no puede considerarse como un lugar idóneo para un paseo ordinario por el parque. La Sentencia en un principio admite que fue la agredida la que entró en el recinto, para más adelante en el afán de liberar a la víctima de cualquier participación en los hechos dice que no queda probado que la misma entrase en el recinto, con lo cual no se entiende cómo pudo morderla el perro, lo que nos lleva a pensar que en la Sentencia de la Audiencia no se aprecia la necesaria relación de causalidad para establecer cualquier tipo de responsabilidad civil, por muy objetiva que ésta sea. Siendo coherentes, debemos pensar que la víctima bien era la propietaria de otro perro y estaba con él, o entró para acariciar al perro agente, que es la alegación de la demandada.

Por otra parte, la tan reiterada insistencia que se hace en la sentencia del hecho de que el perro no llevaba bozal ni estaba atado, debe situarse en su justa medida. El bozal y la correa son medios a utilizar en los supuestos de perros potencialmente peligrosos, pero nada en las actuaciones hace pensar que fuera éste el caso. Es cierto que todos los animales son "potencialmente peligrosos", pero nuestra normativa ha acotado la aplicación del término estableciendo criterios objetivos.

Así, la Ordenanza citada más arriba, en el Artículo 24, regula las condiciones de los perros en la vía y en los espacios públicos y establece que:

3. Los perros potencialmente peligrosos deben cumplir las siguientes condiciones adicionales cuando circulen por la vía y los espacios públicos:

a) Llevar un bozal apropiado a la tipología racial de cada animal.

b) Ir atados por medio de un collar y una correa o cadena que no sea extensible y de 
longitud inferior a 2 metros, y que no ocasione lesiones al animal..."

Sin embargo, el perro de la sentencia comentada no reúne las características de peligrosidad según están establecidas en la Ley de Tenencia de Perros Peligrosos de Cataluña (Ley 10/1999, de 30 de julio $)^{8}$, que en su Art. 1 establece:

\section{“Definición:}

Tienen la consideración de perros potencialmente peligrosos, y les es de aplicación la presente Ley, aquellos que presenten una o más de las siguientes circunstancias:

a) Perros que han tenido episodios de agresiones a personas $u$ a otros perros.

b) Perros que han sido adiestrados para el ataque y la defensa.

c) Perros que pertenecen a una de las siguientes razas o a sus cruces: bullmastiff, dobermann, dogo argentino, dogo de Burdeos, fila brasileiro, mastín napolitano, pit bull, de presa canario, rottweiler, terrier staffordshire americano y tosa japonés."

No consta en las actuaciones que el perro agresor, un husky siberiano, hubiera protagonizado con anterioridad episodios agresivos, ni que haya sido adiestrado para el ataque o defensa, ni pertenece a ninguna de las razas consideradas potencialmente peligrosos. En consecuencia, la propietaria del perro no incumplía ninguna norma de seguridad al dejar al perro en el "pipican" sin bozal y sin tenerlo sujeto a su lado con una correa.

De lo anterior se infiere que es muy probable que los hechos acaecieran tal como describe la demandada en sus alegaciones. Deducción que no encaja por lo visto con el parecer de los Juzgadores, o que a pesar de contemplar el mismo escenario, luego lo interpretan de forma distinta. Efectivamente, la Sentencia dice textualmente: “...no se aprecia ningún tipo de culpa por parte de la lesionada, puesto que el hecho de que entrase en el recinto, aunque la misma se acercase al animal (que insistimos no queda probado) no desplaza la responsabilidad hacia la misma...", con lo cual parece que los hechos sí están claros para los juzgadores, a pesar de la insistencia en darlos por no probados.

\section{Responsabilidad objetiva en aplicación del artículo 1905 CC.-}

La segunda cuestión a plantear es la responsabilidad objetiva a partir de la aplicación del art. 1905 CC.

La responsabilidad civil derivada de delito o falta puede hacerse efectiva en el procedimiento penal siempre que la sentencia sea condenatoria y el actor no haya hecho reserva de la acción civil para hacer efectiva la responsabilidad civil por dicha vía. En cualquier caso, nos hallamos ante supuestos de responsabilidad civil derivada de delito o falta, es decir, la responsabilidad civil derivada de un "ilícito penal".

Sin embargo, en el caso que nos ocupa, tal como aclara la sentencia comentada, no se trata de responsabilidad civil derivada de un ilícito penal, porque la propietaria del perro fue absuelta. En consecuencia, la posibilidad de acudir a la vía civil para intentar hacer efectiva una

${ }^{8}$ http://www.derechoanimal.info/bbdd/Documentos/462.pdf 
responsabilidad por daños tiene su origen en un posible "ilícito civil". Lo anterior implica que el análisis de esta Sentencia ha de llevarse a cabo partiendo de esta premisa: "ilícito civil", al que le es aplicable la regulación de la responsabilidad civil extracontractual contenida en el CC a partir del art. 1902 y siguientes, y especialmente en el caso en cuestión la del art. 1905 CC, que debe ser interpretado no de forma aislada sino de acuerdo con las demás normas civiles, teniendo en cuenta la estructura de la responsabilidad civil extracontractual.

Como es sabido, la responsabilidad civil extracontractual sólo es exigible si se cumplen determinados requisitos previos: acción u omisión del agente, daño sufrido por la víctima y nexo causal entre la acción y el resultado dañoso. Solamente si en este análisis previo coinciden todos los requisitos podemos tratar de la responsabilidad por el daño causado. La responsabilidad objetiva atribuida al art. 1905 CC no supone prescindir de la estructura básica de la responsabilidad civil extracontractual, es decir, que el responsable del agente, en este caso la dueña del perro, tendrá en contra la presunción de que no actuó con la diligencia debida y por tanto es culpable, pero esta presunción es iuris tantum, de manera que el art. 1905 CC invierte la carga de la prueba haciendo que sea la parte demandada quien debe probar el hecho que le exonere de responsabilidad, que al tratarse de responsabilidad objetiva sólo es posible si se dan las interferencias adecuadas en el nexo causal, que para el caso serán fuerza mayor o culpa de la víctima.

Precisamente esta cuestión previa ha sido explicada de forma reiterada por la doctrina jurisprudencial. La Sentencia del TS de 20-12-2007 ${ }^{9}$ (citada en la Jurisprudencia menor en innumerables casos) explica que: "La jurisprudencia ha destacado el carácter objetivo de esta responsabilidad, basada en el riesgo consustancial a la tenencia o a la utilización en propio provecho de los animales, la cual exige tan sólo una causalidad material, estableciendo la presunción de culpabilidad del poseedor del animal o de quien se sirve del mismo por su mera tenencia o utilización, con la única exoneración de los casos de fuerza mayor o de culpa del perjudicado...", y continúa explicando dicha Sentencia: "Esta imputación objetiva de la responsabilidad, derivada de la posesión o utilización del animal, desplaza hacia quien quiere exonerase de ella la carga de acreditar que el curso causal se vio interferido por la culpa del perjudicado, que se erige de ese modo en causa eficiente y adecuada del resultado lesivo producido, eliminado la atribución de éste, conforme a criterios objetivos de imputación, al poseedor del animal o a quien se sirve de él. La presencia de la culpa de la víctima sitúa la cuestión de la atribución de la responsabilidad en el marco de la causalidad jurídica, presupuesto previo al de la imputación subjetiva, que exige la constatación de una actividad con relevancia causal en la producción del daño, apreciada con arreglo a criterios de adecuación o de eficiencia, e implica realizar un juicio de valor para determinar si el resultado dañoso producido es objetivamente atribuible al agente como consecuencia de su conducta o actividad, en función de las obligaciones correspondientes al mismo, contractuales $o$ extracontractuales, y de la previsibilidad del resultado lesivo con arreglo a las reglas de la experiencia, entre otros criterios de imputabilidad admitidos,...".

Aplicando la doctrina anterior al caso comentado, es necesario analizar el comportamiento de la víctima para poder establecer la nitidez del nexo causal.

\footnotetext{
${ }^{9}$ http://www.derechoanimal.info/bbdd/Documentos/1326.pdf
} 
Como se ha explicado el perro estaba dentro del "pipican", lugar que según la normativa analizada es un espacio público, pero cualificado, porque como anuncia la Ordenanza se trata de "espacios reservados a los animales de compañía" para una determinada utilización. En consecuencia, no es cualquier espacio público idóneo para el paseo, el goce y disfrute del paisaje, para el uso de las personas en general. Parece que esta matización no ha sido tomada en consideración por la Audiencia, dándole el mismo tratamiento que a los espacios no cualificados. Es más, textualmente la Sentencia comentada declara que la conducta de la víctima al entrar en el "pipican" no interfiere en absoluto en la responsabilidad de la demandada, confundiendo claramente la responsabilidad objetiva con la causalidad jurídica.

Siguiendo este razonamiento, la imprudencia de la víctima deberá pagarla el responsable del agente en función de la responsabilidad objetiva. Evidentemente no es ésta la solución pertinente (en este sentido, entre otras, las SS. AP Madrid 16-6-2008 ${ }^{10}$, AP Valencia 25-5-2009 y la ya citada del TS 20-12-2007).

En segundo lugar, la persona agredida se metió en el "pipican", y es de suponer que debía tener algún interés que podría explicar mejor la secuencia de los hechos, pero que es desconocido. Sin embargo, partiendo de los datos que proporciona la Sentencia, el perro mordió a la víctima en la cara. Un perro husky siberiano mide aproximadamente desde la cruz, alrededor de $53 \mathrm{~cm}$.; no consta que el perro atacara a la víctima saltando, luego la víctima no estaba de pie, lo que hace factible la explicación de la demandada de que la víctima intentaba tranquilizar al perro, por lo tanto tuvo que agacharse. Es decir, una persona desconocida intenta acariciar a un perro que estaba nervioso dentro de un "pipican", para lo cual se le acerca y se pone a su altura y éste no escapa sino que la muerde. No son hechos probados en sentido estricto, sino deducidos de la propia sentencia.

Existen en el ámbito del Derecho Privado y para este caso cabe señalar en el Derecho Civil, unos índices medios de comportamiento que se presumen correctos y que, por muy anticuado que parezca el término, refleja perfectamente el comportamiento que se espera de cualquier ciudadano corriente, que es el "comportamiento del buen padre de familia". Pues bien, la actuación de la víctima metiéndose en el "pipican", un espacio con animales haciendo sus necesidades, y acercándose a un perro desconocido, no demuestra la utilización de este nivel medio de diligencia exigible al buen padre de familia. Baste para ello pensar en el caso de que la acción intentara llevarla a cabo un menor e imaginar como actuarían sus padres: sin duda sacando al niño del "pipican" o no dejando que entrara en él. Lo anterior, en definitiva, permite calificar la conducta de la víctima como negligente. Teniendo en cuenta que en el ámbito de la responsabilidad civil extracontractual, negligencia y culpa son equivalentes, esta culpa de la víctima debe incardinarse en la relación causal, tal como se ha explicado en la transcripción de la STS.

Muchos animales pueden causar daños, no sólo los perros, especialmente si se interfiere en sus conductas habituales y más si no conocen a las personas que se les acercan. Ésta podría ser una máxima de la experiencia, muy evidente para cualquier persona adulta y muy conocida por las personas que tienen o han tenido perros. El riesgo existe en cualquier actuación que

${ }^{10} \underline{\text { http://www.derechoanimal.info/bbdd/Documentos/1327.pdf }}$ 
implique el trato con animales. Ser responsable es una obligación de todas las personas que convivimos en esta sociedad en la que el riesgo está implícito.

Siguiendo con el comentario de la Sentencia, vamos a analizar la responsabilidad del poseedor o dueño del animal causante del daño.

La persona propietaria o poseedora del animal, está obligada a observar una conducta que evite cualquier daño a personas o cosas como resultado de la acción del agente. En este sentido la Ordenanza más arriba mencionada deja claro que "Las personas poseedoras deberán vigilar a sus animales de compañía y evitar molestias a las personas y a otros animales que compartan ese espacio."

En el supuesto de que se produzcan daños, y éstos, después del análisis de la serie causal, resulten indemnizables, el art. 1905 CC establece que: "el poseedor de un animal o el que se sirve de él, es responsable de los perjuicios que causare, aunque se le escape o extravíe. Sólo cesará esta responsabilidad en el caso de que el daño proviniera de fuerza mayor o de culpa del que lo hubiese sufrido".

No hay duda de la responsabilidad objetiva del poseedor del animal, contemplada en el art. 1905 CC. Sin embargo, en el caso estudiado existe una interferencia en la serie causal producida por la negligente acción de la víctima.

El poseedor o dueño del animal está obligado a prevenir el daño que éste pudiera causar a terceros, personas o bienes, y a indemnizarlos en virtud de su responsabilidad, pero a lo que no está obligado es a suplir la negligencia de terceros que de forma irresponsable, negligente o culposa se coloquen en una situación que propicie la producción del daño.

Para el caso que comentamos, la actuación de la víctima ha sido lamentable. Ya sé que no es de recibo y que se trata de una teoría caducada, pero la situación hace pensar en la teoría medieval sobre la causa: "la causa de la causa es la causa del mal causado". Si la víctima no hubiera actuado, no habría habido daño.

En cuanto a la prueba que debía aportar la demandada acerca de la actuación de la demandante, el único indicio que consta es la referencia en la Sentencia Penal, en cuyo procedimiento no era relevante, pero sí en el juicio civil. La Audiencia conoce y tiene en cuenta para desestimar la alegación de la apelada los razonamientos jurídicos que narran los hechos, no porque sean falsos - que no lo son si la Sentencia Penal los utiliza como tales - sino porque son obiter dicta, en lugar de incluir la información en la serie causal. Pero claro, es que no analiza el nexo causal, se limita a considerar que la responsabilidad objetiva consiste en que la demandada no tiene defensa alguna, sin tener en cuenta el tenor literal del art. 1905 CC, que no detalla el grado de intervención de la víctima para exonerar de responsabilidad al agente. Evidentemente, existen una pluralidad de actuaciones de la víctima que van desde su culpa exclusiva que rompería el nexo causal, hasta la concurrencia de culpas, graduable según cada supuesto. Baste recordar en este sentido la abundante Jurisprudencia que trata del tema (entre otras AP Madrid 16-6-2008). 


\section{dA derecho ANIMAL}

Por otra parte es cierto que la demandada habría podido aportar posiblemente desde el primer momento testificales que corroboraran las afirmaciones alegadas. No se escapa la dificultad de encontrar tales pruebas especialmente tratándose de un segundo juicio y haber transcurrido un plazo de tiempo considerable desde la producción de los hechos.

En definitiva, la Sentencia comentada se limita a confirmar la de Instancia, pero no lleva a cabo el análisis de los requisitos inherentes a la responsabilidad civil extracontractual, en especial las interferencias en el nexo causal, cuestión que permite perfectamente el art. 1905 CC al referirse a la culpa de la víctima, sin que ello deba suponer necesariamente romper la relación causal, pero sí matizar debidamente la intervención que en el resultado final ha tenido la conducta negligente de la víctima, ajustando de esta manera la responsabilidad de la parte demandada. Precisamente por ello, confunde la responsabilidad objetiva con la causalidad jurídica, eliminando cualquier escollo que pudiera dar pie a un análisis más ajustado, para lo cual lleva a cabo aseveraciones gratuitas sin ningún fundamento.

Bellaterra, Noviembre de 2013 